\title{
Correction to: Relative Importance of Climate, Soil and Plant Functional Traits During the Early Decomposition Stage of Standardized Litter
}

Nicolas Fanin, ${ }^{1 *}$ Sophie Bezaud, ${ }^{1}$ Judith M. Sarneel, ${ }^{2,3}$ Sébastien Cecchini,${ }^{4}$ Manuel Nicolas, ${ }^{4}$ and Laurent Augusto ${ }^{1}$

${ }^{1}$ INRAE, UMR 1391 ISPA, Bordeaux Sciences Agro, 33882 Villenave-d'Ornon Cedex, France; ${ }^{2}$ Department of Ecology and Environmental Science, Umea University, Umea , Sweden; ${ }^{3}$ Departement of Biology, Utrecht University, Padualaan 8, 3584 CH Utrecht, The Netherlands; ${ }^{4}$ Department RDI, ONF, 77300 Fontainebleau, France

CORRECTION TO: ECOSYSTEMS (2020) 23:

1004-1018

https://doi.org/10.1007/

s10021-019-00452-z

This paper appeared with an incorrect figure 4; the corrected figure is presented here:

Published online 25 March 2021

The original article can be found online at https://doi.org/10.1007/s100 21-019-00452-z 
A

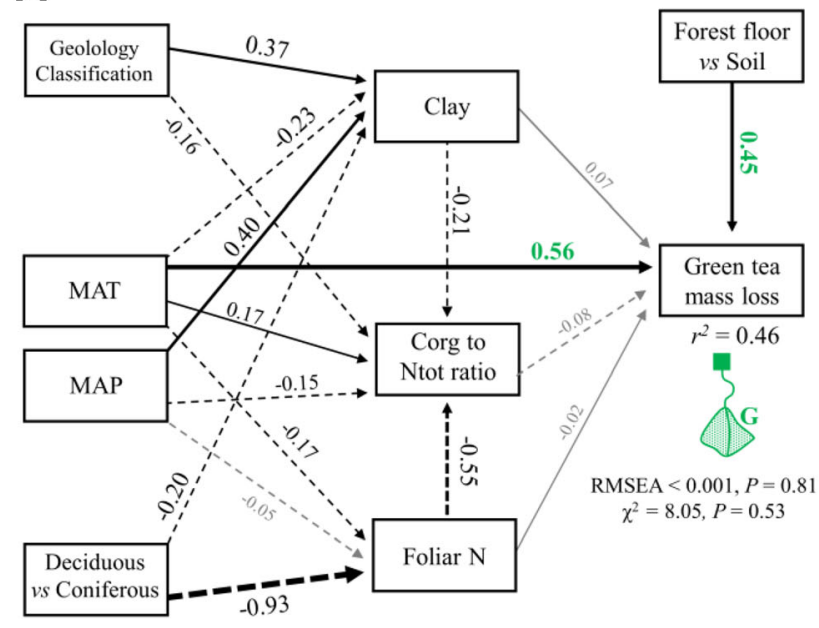

B

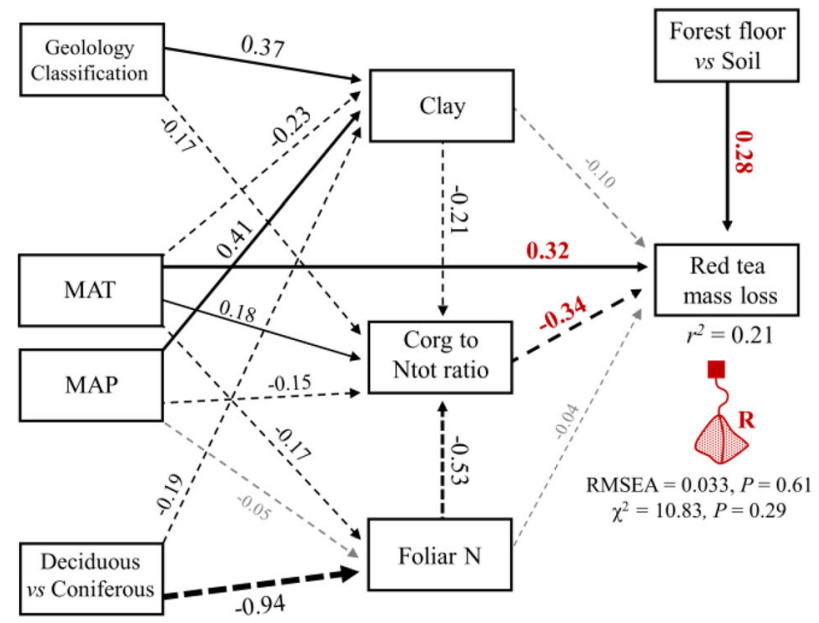

Figure 4. Structural equation model depicting the effects of climate, edaphic factors, plant functional types and soil position on mass loss of $\mathbf{A}$ green tea or $\mathbf{B}$ red tea. Arrow width is proportional to the standardized path coefficient, indicated by a number next to the line. Solid and dashed arrows are used for positive and negative effects, respectively. The $r^{2}$ values represent the proportion of total variance explained for the dependent variable of interest.

Publisher's NoteSpringer Nature remains neutral with regard to jurisdictional claims in published maps and institutional affiliations. 